\title{
Complutum
}

ISSN: 1131-6993

\section{"España se ha estrenado en el campo de la Arqueología de Tierra Santa" Mogaret Dalal (1960-1961)}

\author{
Jordi Vidal ${ }^{2}$
}

Recibido: 07 de septiembre de 2019 / Aceptado: 08 de abril de 2019.

Resumen. En el presente artículo se estudia la correspondencia entre Joaquín González Echegaray y Julio Martínez Santa-Olalla, relacionada con las excavaciones en Mogaret Dalal (1960-1961), las primeras excavaciones en Oriente dirigidas por un arqueólogo español. Dicho estudio permite conocer mejor los métodos de trabajo de González Echegaray, las relaciones sociales y académicas que condicionaros sus trabajos en Jordania, así como su proyecto inédito de excavar en el yacimiento de Tulul adh-Dhahab (Penuel).

Palabras Clave: Joaquín González Echegaray; Arqueología Bíblica; Julio Martínez Santa-Olalla; Tulul adh-Dhahab; Penuel.

\section{[en] "España se ha estrenado en el campo de la Arqueología de Tierra Santa” Mogaret Dalal (1960-1961)}

\begin{abstract}
In this paper we analyzed the correspondence between Joaquín González Echegaray and Julio Martínez Santa-Olalla, related to the excavations in Mogaret Dalal (1960-1961), the first excavations in the Near East conducted by a Spanish archaeologist. This study allows us to better understand González Echegaray's work methods, the social and academic relations that conditioned his work in Jordan, as well as his unpublished project to excavate in Tulul adh-Dhahab (Penuel).

Keywords: Joaquín González Echegaray; Biblical Archaeology; Julio Martínez Santa-Olalla; Tulul adh-Dhahab; Penuel
\end{abstract}

Sumario: 1. Introducción. 2. Mogaret Dalal: diplomacia, publicaciones y relaciones académicas. 3. Mogaret Dalal en la prensa española. 4. Un proyecto sin concretar: excavaciones en Tulul adh-Dhahab (Penuel). 5. Consideraciones finales. 6. Bibliografía.

Cómo citar: Vidal, J. (2019): "España se ha estrenado en el campo de la Arqueología de Tierra Santa” Mogaret Dalal (1960-1961). Complutum, 30(1): 29-41.

\section{Introducción}

El título del presente artículo es una frase literal extraída de una carta de Joaquín González Echegaray dirigida a Julio Martínez Santa-Olalla el 24 de diciembre de 1960 (Ayun- tamiento de Madrid. Museo de San Isidro. JMSO 40/6/24112). De esa forma, González Echegaray reivindicaba la importancia histórica de las excavaciones que, entre diciembre de 1960 y enero de 1961, llevó a cabo en la cueva de Mogaret Dalal (Jordania), al tratarse

\footnotetext{
Artículo escrito en el marco del proyecto de investigación "Origen de la Orientalística Antigua en España” (HAR2017-82593-P). Agradezco a Amalia Pérez Navarro (Museo de San Isidro, Madrid), su ayuda en la consulta de la correspondencia de Julio Martínez Santa-Olalla; y a Àngels Casanovas Romeu (Museu d'Arqueologia de Catalunya), su ayuda en la consulta de la correspondencia de Martín Almagro Basch.

2 Universitat Autònoma de Barcelona jordi.vidal.palomino@uab.cat
} 
de la primera misión arqueológica en el Próximo Oriente dirigida por un arqueólogo español. De aquella forma, consideraba González Echegaray, España se incorporaba por fin al redescubrimiento arqueológico del Próximo Oriente Antiguo, iniciado en el siglo XIX por diplomáticos y arqueólogos franceses, ingleses, alemanes y norteamericanos principalmente (Chevalier 2012).

Como ya se ha apuntado en diversos lugares, el estudio de la documentación de archivo ofrece interesantes aportaciones para la historia de la arqueología, por cuanto permite, entre otros, conocer con detalle los métodos de trabajo empleados, averiguar datos, ideas o proyectos que, por las circunstancias que sean, finalmente no fueron publicados, así como reconstruir las relaciones sociales y académicas que, en mayor o menor medida, condicionaron el desarrollo de las investigaciones (Schlanger y Nordbladh 2008). De acuerdo con estos planteamientos, el presente artículo se basa principalmente en el análisis de tres cartas enviadas por González Echegaray a Martínez Santa-Olalla, y conservadas en el Museo de San Isidro de Madrid: JMSO 40/6/24112 (Jerusalén, 24 de diciembre de 1960; texto manuscrito), JMSO 40/6/24113 (Jerusalén, 12 de enero de 1961; texto mecanografiado; firma y postdata autógrafas) y JMSO 40/5/24061 (Santander, 10 de marzo de 1961; texto mecanografiado; firma autógrafa; encabezado impreso: Excma. Diputación Provincial de Santander / Museo prehistórico / El vice-director). No incluimos en el presente estudio la carta JMSO 40/6/24107 (Santander, 2 de abril de 1961), por cuanto no guarda relación con el tema objeto del artículo.

El estudio de dicha correspondencia, como se mostrará a continuación, permite aportar distintos elementos que mejoran notablemente nuestro conocimiento acerca de la intrahistoria de aquella primera excavación arqueológica española en el Próximo Oriente.

Los personajes principales de este texto, obviamente, son los dos protagonistas del epistolario analizado. El sacerdote Joaquín González Echegaray (1930-2013), como ya se ha apuntado, ocupa un lugar destacado en la historia de la arqueología española, sobre todo por su actividad pionera en el Próximo Oriente, pero también por sus importantes contribuciones en otros campos, como la prehistoria cántabra (Palacio-Pérez 2013; Straus 2013; Vidal 2013: 65ss.; González Urquijo e Ibáñez 2015). Dis- cípulo del también arqueólogo P. Jesús Carballo, se formó, entre otros, en la Universidad de Barcelona, el Pontificio Istituto Biblico de Roma y la École Biblique de Jerusalén, donde fue discípulo de Roland de Vaux. González Echegaray fue uno de los primeros miembros del Instituto Español Bíblico y Arqueológico en Tierra Santa, más conocido como la Casa de Santiago, institución creada en 1955 por monseñor Romero de Lema para promover los estudios bíblicos avanzados, siguiendo el modelo establecido por la École Biblique (Sánchez Caro y Calvo 2015). Aunque ocupó cargos importantes en instituciones académicas, como la subdirección del Museo de Prehistoria de Cantabria o la dirección del Museo de Altamira, lo cierto es que González Echegaray nunca pudo contar con un verdadero equipo ni con los medios adecuados para desarrollar de forma eficaz sus líneas de investigación en el Próximo Oriente (González Urquijo e Ibáñez 2015: 175), lo que limitó notablemente el impacto de las mismas.

Por su parte, Julio Martínez Santa-Olalla (1905-1972) fue uno de los arqueólogos españoles más destacados e influyentes durante el primer franquismo, desde su puesto de Comisario General de Excavaciones Arqueológicas. Discípulo de Pere Bosch Gimpera y Hugo Obermaier, se dedicó principalmente a la prehistoria de la Península Ibérica (Ortega y Quero 2002; Gracia 2009; Mederos y Escribano 2011; Roldán y Blánquez 2012), aunque diversos episodios de su biografía lo relacionan directamente con la arqueología del Próximo Oriente. Así, por ejemplo, el 16 de mayo de 1949 escribía a Gonzalo Diéguez, el entonces ministro de España en Jordania, para tantear la posibilidad de que el Seminario de Historia Primitiva del Hombre de la Universidad de Madrid, que dirigía el propio Martínez Santa-Olalla, llevase a cabo en dicho país una misión arqueológica. Como se observa en el pasaje de la carta que transcribimos a continuación, más que un verdadero proyecto arqueológico, Martínez Santa-Olalla estaba planteando una idea todavía en un estado muy embrionario, que justificaba científicamente por la importancia que, en su opinión, tenía el estudio de la prehistoria jordana para una mejor comprensión de la prehistoria de la Península Ibérica. Por desgracia, no conocemos cuál fue la respuesta de Diéguez, si es que la hubo, aunque está claro que la propuesta no llegó a concretarse sobre el terreno: 
Por cierto que pudiera ocurrir que entrase dentro de la [sic.] posibilidades de nuestro Seminario, gracias a una ayuda económica privada, el realizar una campaña de excavaciones en Transjordania, en alguna de las localidades prehistóricas que tanto interés tienen para España. ¿Sería Vd. tan amable de informarme previo un "globo sonda", como se nos recibiría en Transjordania y en que condiciones se nos autorizaría la excavación? (Ayuntamiento de Madrid. Museo de San Isidro. JMSO 40/6/2692)

Sí se concretó, en cambio, la creación por parte de Martínez Santa-Olalla de una de las más importantes colecciones de antigüedades mesopotámicas presentes en España. El origen de dicha colección fue un intercambio privado de piezas acordado con Naji al-Asil, director general de Antigüedades de Irak. Según se estipulaba en el acuerdo entre ambos, Martínez Santa-Olalla entregó a al-Asil un total de 790 piezas de su colección arqueológica particular, obteniendo a cambio un lote de 190 objetos arqueológicos mesopotámicos, entre los que figuraban recipientes y fragmentos cerámicos, estatuillas, pesas de telar, cabezas de maza, sellos cilíndricos y tres ladrillos de fundación con inscripciones de Gudea, Amar-Sin y Nabucodonosor II. A su muerte, dicha colección reportó importantes beneficios económicos a los herederos de Martínez Santa-Olalla, quienes la vendieron al Museo Arqueológico Nacional por 20 millones de pesetas (Vidal 2014).

En cualquier caso, ese bien atestiguado interés arqueológico y anticuarista de Martínez Santa-Olalla en el Próximo Oriente Antiguo sirve para contextualizar la buena disposición que desde un primer momento mostró hacia las excavaciones de González Echegaray en Jordania, atestiguado en la correspondencia que se estudia a continuación.

\section{Mogaret Dalal: diplomacia, publicaciones y relaciones académicas}

Mogaret Dalal es el nombre con el que el propio González Echegaray bautizó a una pequeña cueva situada unos 12 kilómetros al suroeste de Jerash, en el norte de Transjordania. Los trabajos arqueológicos en la misma se llevaron a cabo entre diciembre de 1960 y enero de 1961, bajo la dirección del propio González Echegaray. Los resultados científicos fueron convenientemente publicados por el director de la misión (González Echegaray 1969-1970), apareciendo con posterioridad diversos resúmenes de los mismos (véase, por ejemplo, González Echegaray 1978a: 4ss.; 1988: 237s. y 2006: 32 ; resulta significativa la ausencia de cualquier referencia a Mogaret Dalal en su obra de síntesis González Echegaray 1978b). Tanto las excavaciones en el interior de la cueva como en la terraza exterior permitieron documentar una larga secuencia de ocupación en el lugar, con industria lítica del Paleolítico Medio, Paleolítico Superior y Neolítico. En este sentido, sin embargo, cabe notar que en las publicaciones más antiguas (González Echegaray 19691970,1978 a y 1988) y en su correspondencia con Martínez Santa-Olalla (JMSO 40/6/24112 y 24113), González Echegaray afirmaba haber identificado materiales del Paleolítico Inferior, aunque en la publicación más reciente y en sus memorias (González Echegaray 2006 y 2015), optaba por omitir cualquier referencia a aquella posible primera fase de ocupación de la cueva. Otros restos cerámicos demuestran que el lugar también fue ocupado de forma esporádica en época romana, bizantina y protoislámica. Encima de la cueva, González Echegaray localizó los restos arquitectónicos de un pequeño monasterio bizantino que ya había sido identificado previamente por el arqueólogo norteamericano Nelson Glueck.

El papel fundamental desempeñado por el diplomático español José Antonio Varela Dafonte en las excavaciones en Mogaret Dalal ha sido reivindicado por el propio protagonista en sus memorias (Varela 1999: 209ss.) y reconocido explícitamente por González Echegaray en su recreación de la historia de aquellas excavaciones (González Echegaray 2015: 166ss.). Así, Varela no tan sólo fue el descubridor del yacimiento, sino que, gracias a sus contactos con Awni Dajani, director del Departamento de Antigüedades de Jordania, logró que las autoridades árabes concediesen los pertinentes permisos de excavación a una misión española, a pesar de la falta de experiencia de campo de los arqueólogos de la Casa de Santiago, así como los recursos económicos necesarios para llevar a cabo las excavaciones. De esta forma lo reconocía el propio González Echegaray a Martínez Santa-Olalla:

El encargado de negocios de España en Amman (ahora no hay embajador) D. José Antonio Varela, descubrió una cueva con muy buen aspecto y dadas sus buenas relaciones con el 
gobierno jordano consiguió no solo la autorización correspondiente, sino incluso la subvención necesaria para hacer allí unos sondeos (Ayuntamiento de Madrid. Museo de San Isidro. JMSO 40/6/24112).

En una carta posterior, González Echegaray ofrecía más detalles sobre el papel fundamental desempeñado por Varela y sus relaciones con Dajani, así como algunas concreciones relacionadas con el acuerdo establecido para la realización de las excavaciones en Mogaret Dalal, especialmente las relacionadas con la publicación de los resultados obtenidos:

Pedí autorizacion al Departamento de antigüedades para hacer unos sondeos en una cueva junto al antiguo Yabok, hoy Wadi Zerqa (Transjordania). Entonces Awni Dajani, que es el jefe del Departamento, y que tiene gran simpatía por España y es amigo del actual encargado de Negocios de España en Ammán, no solamente autorizó sino que ofreció dinero del Departamento para lo que fuera necesario. Nosotros entonces le dijimos, que se trataba sólo de un sondeo previo y convinimos en hacerlo, pagando él los gastos y nombrándome a mí director de las excavaciones con el compromiso de publicar después los resultados en el Boletín del Departamento (Ayuntamiento de Madrid. Museo de San Isidro. JMSO 40/6/24113).

Queda claro, por lo tanto, que el acuerdo con el Departamento de Antigüedades jordano implicaba la obligación por parte de González Echegaray de publicar los resultados de las excavaciones en el Annual of the Department of Antiquities of Jordan (ADAJ), el foro de difusión arqueológica creado por el departamento jordano en 1951. Sin embargo, y a pesar de la existencia de dicho acuerdo, González Echegaray nunca llegó a publicar dichos resultados en el ADAJ, sino que optó por presentarlos en la revista Ampurias (González Echegaray 1969-1970). Dicho incumplimiento probablemente estuvo pactado con Dajani, pues solo así se explican las buenas relaciones que en los años posteriores González Echegaray mantuvo con las autoridades arqueológicas jordanas. Las causas de la inobservancia de aquel compromiso pueden intuirse a través de la correspondencia con Martínez Santa-Olalla. En un alarde de sinceridad, González Echegaray reconocía el valor científicamente limitado de las excavaciones realizadas en Mogaret Dalal:
Y ahora paso a hablarle en tono más confidencial. El resultado no ha sido espectacular (...) El Departamento de Antigüedades está conforme con los resultados de esta primera campaña de prospección, a pesar de que como digo no hemos tenido la suerte de encontrar cosas extraordinarias (Ayuntamiento de Madrid. Museo de San Isidro. JMSO 40/6/24113).

Seguramente, en función de dichos resultados y de acuerdo con Dajani, González Echegaray llegó a la conclusión de que no valía la pena preparar una publicación en inglés o en francés para ADAJ, considerándose suficiente el breve texto presentado en castellano en $\mathrm{Am}$ purias casi una década después de la realización de las excavaciones.

El otro diplomático mentado en la correspondencia aquí analizada es Juan Manuel Adriansens, nombrado embajador en Jordania en 1961, después, por lo tanto, de que hubiesen tenido lugar las excavaciones en Mogaret Dalal. No obstante, en opinión de González Echegaray, Adriansens, gracias a su sensibilidad hacia las investigaciones arqueológicas, podía ser una figura clave para conseguir solucionar uno de los grandes problemas que afectaba a sus proyectos futuros en Jordania, esto es, la falta de recursos económicos para financiar las excavaciones previstas, por lo que instaba a Martínez Santa-Olalla a contactar rápidamente con él:

Tampoco estaría de más, que si Ud. lo cree oportuno, hablara con el nuevo embajador en Amman. Se llama Adriansens y ha sido hasta ahora jefe de Cifra en el Ministerio. Todavía no ha salido de España y podría ser interesante tenerle ya bien dispuesto. Pero esto habría que hacerlo urgentemente porque creo está ya para venir de un momento a otro. Es hombre segun mis noticias a quien se puede interesar por la Arqueología y esto seria un paso importante (Ayuntamiento de Madrid. Museo de San Isidro. JMSO 40/6/24113).

En cualquier caso, y más allá de los detalles concretos, la importancia que jugó la diplomacia en el transcurso de las primeras excavaciones españolas en el Próximo Oriente atestigua bien la realidad del momento histórico, cuando el régimen franquista, sobre todo en sus momentos de mayor debilidad en el concierto político internacional, estaba especialmente interesado en potenciar las relaciones políticas 
con el mundo árabe y en difundir la cultura española en la región a través de los distintos centros culturales existentes (Pérez 2007: 29; Hernando 2015: 17).

Por lo que se refiere a las relaciones sociales y académicas vinculadas con las excavaciones en Mogaret Dalal, lo cierto es que la correspondencia de González Echegaray con Martínez Santa-Olalla permite apreciar diversos elementos del todo ausentes en la bibliografía. Un buen ejemplo de ello lo encontramos en las críticas vertidas sobre el trabajo previo de Nelson Glueck (1939: 223) en aquella misma zona:

Nelson Gluek [sic], por ejemplo, no hizo excavaciones, sino que se contentó con recorrer las zonas, consignar lo que veía y recoger las cosas que encontraba por el suelo, y aun así todo se le escapó en nuestro caso: la cueva, el yacimiento paleolitico de superficie y la torre de defensa de la ruina. Del edificio mayor dice dos palabras pero ni siquiera presenta plano alguno ni concreta nada (Ayuntamiento de Madrid. Museo de San Isidro. JMSO 40/6/24113.).

Como se aprecia en el pasaje anterior, González Echegaray optó por reivindicar la calidad y el valor de su labor mediante un recurso muy habitual en el ámbito académico, el de destacar la superioridad del trabajo propio respecto al llevado a cabo por los predecesores. En este caso, recriminaba a Glueck tanto la metodología utilizada ("se contentó con recorrer las zonas, consignar lo que veía y recoger las cosas que encontraba por el suelo") como la falta de precisión en la prospección llevada a cabo ("y aun así todo se le escapó en nuestro caso"). La crítica a Glueck parece, desde luego, un tanto exagerada, pues resulta obvio que una prospección extensiva como la que llevó a cabo en Transjordania, que permitió la localización de más de 1000 yacimientos arqueológicos en la zona, no podía obtener los mismos resultados que una excavación específica como la practicada por González Echegaray en Mogaret Dalal. En este sentido es importante recordar que todavía hoy, y a pesar de sus deficiencias, la obra de Glueck en Transjordania se sigue reivindicando como un punto de referencia ineludible (Brown y Kutler 2005). Aunque no existe ninguna evidencia documental de ello, no puede descartarse la posibilidad de que la exagerada crítica por parte de González Echegaray tuviese también un cierto trasfondo personal y confesional, teniendo en cuenta la condición de rabino de Glueck y de sacerdote católico de González Echegaray.

Otro aspecto interesante que aparece en la correspondencia con Martínez Santa-Olalla son las complicadas relaciones que González Echegaray mantuvo en aquella época con su antiguo maestro, Martín Almagro Basch, en el contexto de sus actividades arqueológicas en Jordania. Esas relaciones difíciles, que analizaremos a continuación, únicamente están atestiguadas en la correspondencia con Martínez Santa-Olalla, sin que exista rastro explícito de las mismas en la documentación oficial o en la bibliografía.

Así, por ejemplo, en sus memorias, González Echegaray se refería en diversos pasajes a Almagro de forma aparentemente neutral. En una primera ocasión, le reconocía como maestro y recordaba la importancia de sus campañas arqueológicas en Nubia, eso sí, puntualizando que sus trabajos en Mogaret Dalal habían sido anteriores a los de Almagro (González Echegaray 2015: 177s.). Más adelante, aunque sin atisbo explícito de crítica, González Echegaray reconocía que las excavaciones de Almagro en Nubia le habían perjudicado a la hora de obtener el apoyo económico de la dictadura franquista para sus propios proyectos arqueológicos en Jordania:

La posibilidad de recabar el apoyo económico del gobierno español resultaba más problemática por cuanto que, por entonces, habían comenzado las excavaciones españolas oficiales en Egipto y Sudán a cargo del profesor M. Almagro, y era mucho esperar tanto interés como para que una España tradicionalmente cerrada sobre sí misma, de repente atendiera a los gastos de dos expediciones científicas en el extranjero sin relación directa con nuestra cultura histórica (González Echegaray 2015: 183).

No obstante, en su correspondencia con Martínez Santa-Olalla, González Echegaray se mostraba mucho más crítico con la figura de Almagro. En primera instancia, resulta interesante notar el orgullo con el que celebraba que sus excavaciones en Mogaret Dalal se hubiesen producido antes que las de Almagro en el Alto Egipto y Nubia:

Me he adelantado a las excavaciones que el equipo de Almagro realiza en Egipto (Ayuntamiento de Madrid. Museo de San Isidro. JMSO 40/6/24113). 
Un hecho que le permitía reclamar para sí mismo el honor de ser el primer arqueólogo español encargado de dirigir una excavación arqueológica en el Próximo Oriente:

He abierto brecha, siendo el primer español que hace excavaciones en Tierra Santa y hasta creo que en todo el Oriente (Ayuntamiento de Madrid. Museo de San Isidro. JMSO 40/6/24113).

Sin embargo, más allá de esa cuestión casi anecdótica, la rivalidad con Almagro tuvo mayor trascendencia. En una de las memorias anuales remitida por Vicente Vilar, director de la Casa de Santiago en Jerusalén, a la Dirección General de Relaciones Culturales del Ministerio de Asuntos Exteriores de Madrid, se hacía referencia a la voluntad expresada por Almagro de colaborar con la institución en futuros proyectos arqueológicos en Jordania:

Además de las visitas habituales de los profesores de l'Ecole Biblique y del Studium Franciscanum, que este año fueron más asiduas, quiso establecer contacto con la Casa de Santiago para estudiar las posibilidades de ulteriores colaboraciones el Profesor D. Martín Almagro, que a tal efecto se trasladó desde Nubia. ("Memoria anual. Curso 1961-62", informe depositado en AGA, Alcalá de Henares, leg. 66/4594).

González Echegaray también se refería a aquel mismo episodio en su correspondencia con Martínez Santa-Olalla, aunque en unos términos muy distintos. Como se aprecia claramente en el pasaje de la carta transcrito a continuación, González Echegaray no vivió el episodio relatado por Vilar como una sincera propuesta de colaboración, sino que acusaba directamente a Almagro de querer arrebatarle sus excavaciones en Jordania, algo a lo que no estaba dispuesto y que confiaba en poder evitar gracias a sus buenas relaciones con el Departamento de Antigüedades jordano:

El asunto es importante porque los de Egipto parece que estan intentando apoderarse tambien de mis cosas en Jordania. No obstante yo estoy alli muy buen situado y me defiendo. Para explicarle todo esto y otras cosas tengo necesidad de hablar con $\mathrm{Vd}$. con alguna urgencia. Yo iría a Madrid para pasar allí un dia. Ahora no puedo ausentarme mas tiempo de aquí. Digame qué dia es bueno para Vd.
(Ayuntamiento de Madrid. Museo de San Isidro. JMSO 40/5/24061).

Para entender correctamente este episodio en su conjunto es necesario tener en cuenta tanto la situación de la arqueología española en aquel momento, especialmente la rivalidad existente entre Martín Almagro Basch y Julio Martínez Santa-Olalla, como los problemas presupuestarios que experimentaba González Echegaray para poder llevar a cabo sus trabajos arqueológicos en Jordania.

En este sentido es importante comenzar recordando un episodio de la biografía de González Echegaray. Discípulo del P. Jesús Carballo, por mediación de éste entró en contacto con Martín Almagro y Lluís Pericot para estudiar con ambos en la Universidad de Barcelona la prehistoria del Levante Peninsular, gracias a la concesión de una pensión por parte de la Diputación provincial de Cantabria (Carta de Jesús Carballo a Lluís Pericot. Santander, 21 de julio de 1950. Fons Lluís Pericot. Biblioteca Nacional de Catalunya). El viaje de estudios, tras diversos retrasos, finalmente se produjo en otoño de 1951:

Muy estimado profesor: Tengo la satisfacción de comunicarle que el Sr. Obispo me ha concedido el permiso para ir a estudiar Prehistoria a Barcelona los dos meses que Vd. indicaba.

El Sr. Almagro me dijo, cuando estuvo aquí en Santander, que el curso de Paleolítico comenzaba el 15 de este mes para terminar el 15 de Diciembre; de modo que procuraré estar ya en Barcelona el día de la apertura de curso (Carta de Joaquín González Echegaray a Lluís Pericot. Santander, 4 de octubre de 1951. Fons Lluís Pericot. Biblioteca Nacional de Catalunya).

La correspondencia con Pericot y con Almagro demuestra que aquella estancia en Barcelona sirvió, entre otros, para que González Echegaray estableciese unas relaciones cordiales con ambos catedráticos. De hecho, en una carta de 1954, González Echegaray felicitaba cordialmente a Almagro por su triunfo, precisamente sobre Martínez Santa-Olalla, en las oposiciones para la obtención de la cátedra de Historia Primitiva del Hombre de la Universidad de Madrid, ocupada de manera interina por Martínez Santa-Olalla desde 1939 (Gracia 2009: 467ss.): 
Distinguido profesor y amigo: Me entero por la prensa de su éxito en las oposiciones de la Catedra de Madrid y me apresuro a darle por ello mi enhorabuena más sincera.

También aprovecho la ocasión para ponerme de nuevo a su disposición para todo aquello en que le pueda ser util desde mi nuevo puesto de Director-Adjunto del Museo de Santander y Jefe del Servicio de Excavaciones de la Diputación.

Ahora que Vd. estará ya en Madrid me será más facil poder entrevistarme y aconsejarme por Vd. (Carta de Joaquín González Echegaray a Martín Almagro Basch. Santander, 2 de noviembre de 1954. Arxiu Històric del Museu d'Arqueologia de Catalunya).

Una felicitación que fue puntualmente agradecida por un Almagro que se mostraba deseoso de poder colaborar con su antiguo discípulo:

Tengo su carta y quiero agradecerle su enhorabuena por el éxito que he logrado obtener en las Oposiciones a la Cátedra de Prehistoria de Madrid.

Será para mi una satisfacción si en algo puedo asesorarle desde mi nuevo cargo en el cual como siempre me tendrá a su disposición (Carta de Martín Almagro Basch a Joaquín González Echegaray. Barcelona, 6 de noviembre de 1954. Arxiu Històric del Museu d'Arqueologia de Catalunya).

A tenor de lo apuntado hasta aquí, se hace más evidente la necesidad de explicar las disputas entre González Echegaray y Almagro, reflejadas en la posterior correspondencia del primero con Martínez Santa-Olalla. En este sentido, el elemento clave fue la participación, en 1953, 1956 y 1957, de González Echegaray en las excavaciones que Martínez Santa-Olalla dirigía en la Cueva de El Pendo (Cantabria) (Palacio-Pérez 2013: 213). Fueron precisamente aquellas excavaciones las que propiciaron su "cambio de bando", iniciando una fructífera colaboración con quien era el gran rival, tanto personal como académico, de Almagro (Gracia 2009: 125s.).

El hecho de que, en ese marco de confrontación, González Echegaray se alinease con Martínez Santa-Olalla en contra de quien había sido su maestro en Barcelona se explica, en buena medida, por el mismo desarrollo de las excavaciones en Jordania. Ya veíamos antes que González Echegaray se refería en sus memorias a los problemas que encontraba para poder financiar sus trabajos arqueológicos en el Próximo Oriente. Una de las razones que apuntaba de manera explícita para explicar aquella situación era el hecho de que la misión de Almagro en Nubia consumía todo el exiguo presupuesto estatal dedicado a la arqueología en el extranjero (cerca de dos millones de pesetas). González Echegaray encontró en la figura de Martínez Santa-Olalla a un aliado para tratar de superar aquellas trabas económicas, debido tanto a sus bien conocidos contactos políticos con los sectores falangistas de la dictadura como a su cargo de director del Instituto Arqueológico Municipal de Madrid (González Echegaray 2015: 183s.).

Está claro que las excavaciones en Nubia le habían reportado a Almagro un enorme prestigio académico a nivel nacional e internacional (Gracia 2012: 320ss.), un prestigio que buscaba reforzar expandiendo su foco de interés hacia Jordania. Finalmente, Almagro trabajó en aquel país en la década de 1970, en yacimientos como la Ciudadela de Amman o el Baño de Qusayr 'Amra (Almagro 2006a y 2006b), aunque al margen de la labor de una Casa de Santiago con la que había tratado de colaborar (Vilar) o que había intentado controlar (González Echegaray) en la década anterior. Así, el apoyo económico que finalmente Martínez Santa-Olalla puso a disposición de González Echegaray resultó clave no solo para acometer sus posteriores trabajos en El-Khiam (Palestina) (González Echegaray 1964-1966), sino también para mantener su independencia respecto a Almagro.

En definitiva, como se puede apreciar en este episodio, las disputas académicas y personales entre dos de los más importantes representantes de la arqueología española de la época, tuvieron una repercusión directa en el desarrollo de la labor arqueológica de González Echegaray en el Próximo Oriente.

\section{Mogaret Dalal en la prensa española}

En su correspondencia con Martínez Santa-Olalla, González Echegaray mostraba un especial interés en que sus trabajos en Mogaret Dalal fuesen difundidos en la prensa generalista española. Ese interés por publicitar su labor, más allá de una posible necesidad personal de 
reconocimiento, estaba sobre todo relacionado con la acuciante obligación de obtener la financiación necesaria para sus futuros proyectos en la región. En este sentido, instaba a Martínez Santa-Olalla para que hiciese lo posible por llamar la atención del Ministerio de Asuntos Exteriores respecto a sus trabajos en Mogaret Dalal:

Pero creo estaría bien que si Vd. tiene ocasión lo aireara un poco por España. Convendría también hacer algo de ambiente en el Ministerio de Asuntos Exteriores (...) Por de pronto acaso convendría que Ud. como Jefe del Servicio de Excavaciones se dirigiera al Ministerio de Asuntos Exteriores pidiéndoles información de mis excavaciones. Allí ellos estan enterados a través de Varela, y el hecho de que Ud. solicitara esa información podría hacerles caer en la cuenta de la importancia que puede tener todo esto (Ayuntamiento de Madrid. Museo de San Isidro. JMSO 40/6/24112).

La vía utilizada para reclamar cobertura mediática fue doble. Por una parte, González Echegaray insistía en el valor científico de sus investigaciones arqueológicas y el avance que suponían para el conocimiento de la prehistoria jordana. Por otra, y ya al margen de consideraciones científicas, apelaba directamente al argumento patriótico, remarcando que sus trabajos servían para situar a España en un lugar que ya hacía décadas que transitaban otros países europeos y americanos.

La cosa tiene importancia, porque a parte de lo que aparezca, el hecho es que España "se ha estrenado" en el campo de la Arqueología de Tierra Santa, donde vienen trabajando otras naciones. Y hoy es esa pequeña cueva y mañana puede ser un tell o cualquier cosa (Ayuntamiento de Madrid. Museo de San Isidro. JMSO 40/6/24112).

En este sentido, confiaba en que Martínez Santa-Olalla convenciese al ministro de Asuntos Exteriores, Fernando María Castiella, acerca de la repercusión propagandística que supondría para España llevar a cabo unas excavaciones en Jordania, especialmente si las mismas tenían lugar en un yacimiento con resonancias bíblicas, una repercusión que él estimaba superior a la lograda por Almagro y sus trabajos en Asuán:
Aquí pues nos encargaríamos nosotros de buscar un sitio a propósito donde excavar y de gestionar las cosas con el Departamento de Antigüedades, ahora bien, para hacer una excavacion en plan necesitaríamos dinero abundante del ministerio y esto es lo que convendría tratar con Castiella, exponiéndole la situacion y haciéndole ver que unas excavaciones en Palestina serían más sonadas y de más propaganda para España que las de Egipto (Ayuntamiento de Madrid. Museo de San Isidro. JMSO 40/6/24112).

Sin embargo, y a pesar de sus esfuerzos en este sentido, la cobertura mediática de las excavaciones en Mogaret Dalal fue limitada, muy lejos, por ejemplo, de la que tuvieron los trabajos dirigidos por Almagro en Nubia ( $\mathrm{Zu}-$ rinaga 2009). En este sentido, únicamente hemos localizado dos noticias al respecto (Arriba 27/12/1960; La Gaceta del Norte 28/12/1960), ya referidas y comentadas por el propio González Echegaray en una de las cartas dirigidas a Martínez Santa-Olalla:

Por su parte la prensa ha comenzado tambien a actuar. Por depronto [sic] en España, en el Arriba de Madrid del 27 de Diciembre se publicó ya una amplia noticia de los trabajos, y segun me dicen de España también ha aparecido algo en la Gaceta del Norte de Bilbao. Las noticias no las he mandado yo y por eso supongo que no seran muy exactas. Pero el hecho es que ya se han enterado en España, aunque creo convendría que aun se enteraran más (Ayuntamiento de Madrid. Museo de San Isidro. JMSO 40/6/24113).

Está claro, por lo tanto, que González Echegaray sobreestimaba la capacidad de generar interés mediático que tenían sus trabajos en un pequeño yacimiento prehistórico como el de Mogaret Dalal, sobre todo en relación a unas excavaciones de la magnitud de las llevadas a cabo en el contexto de la construcción de la presa de Asuán. Seguramente, el propio González Echegaray era consciente de esta situación. De ahí que, de cara al futuro, se plantease la posibilidad de excavar un yacimiento directamente relacionado con la Arqueología Bíblica, un yacimiento que, esta vez sí, podría proporcionarle una mayor repercusión mediática y ayudarle a lograr la tan ansiada ayuda económica procedente del Ministerio de Asuntos Exteriores. 


\section{Un proyecto sin concretar: excavaciones en Tulul adh-Dhahab (Penuel)}

Como apuntábamos al principio, el estudio de la correspondencia entre González Echegaray y Martínez Santa-Olalla también nos permite conocer la planificación de algunos proyectos arqueológicos que, finalmente, no se llevaron a cabo. González Echegaray consideraba el trabajo realizado en Mogaret Dalal como el paso previo necesario para demostrar a las autoridades jordanas su capacidad como arqueólogo y así poder acometer en el futuro trabajos de mayor envergadura.

El Departamento de Antigüedades se ha enterado de que los españoles tambien sabemos excavarr [sic] con tan buena técnica como cualquiera. (Dajani visitó las excavaciones y quedo muy bien impresionado del rigor científico con que lo llevabamos todo) (Ayuntamiento de Madrid. Museo de San Isidro. JMSO 40/6/24113).

Hoy sabemos que el paso siguiente emprendido por González Echegaray fueron las excavaciones en la terraza de El-Khiam en 1962 (González Urquijo e Ibáñez 2015). Sin embargo, en la correspondencia aquí analizada se aprecia cómo aquella no fue la primera opción que contempló. En realidad, su interés primero fue el de intentar las excavaciones en el yacimiento de Penuel, tal y como se lo reconocía a Martínez Santa-Olalla:

Se me ocurre que el lugar más a propósito para comenzar unas excavaciones de verdadero prestigio sería el valle del Jordán, donde hay todavía muchos tells intactos. La experiencia de Jericò [sic] ha sido fantásttica [sic] con la famosa ciudad neolitica precerámica del año $7.000 \mathrm{a}$. de C. y probablemente los otros tells nos daran algo parecido (...). Se me ocurre que nostros podríamos hacer las excavaciones en Penuel, que está a la entrada del Yabok viniendo desde el Jordán y que es ademas un lugar bíblico. Está en un sitio un poco apartado, pero es un tell fantástico que todavía nadie ha visto a excepción de de Vaux y Gluek [sic] y que hablan de él como de algo extraordinario. En fin, no conviene adelantar acontecimientos. De todos modos desde aquí iremos viendo poco a poco posibles sitios (Ayuntamiento de Madrid. Museo de San Isidro. JMSO 40/6/24113).
Penuel es una antigua ciudad bíblica, que aparece mencionada en diversos pasajes del Antiguo Testamento (Génesis 32: 30 y 31; Jueces $8: 8$ y 17; 1 Reyes 12: 25). Aunque González Echegaray no daba el nombre actual del yacimiento que pretendía excavar, al referirse a Penuel tenía en mente Tulul adh-Dhahab, situado unos $35 \mathrm{~km}$ al noroeste de Amman y tradicionalmente identificado con aquella localidad bíblica (Slayton 1992). En su carta, González Echegaray reivindicaba la importancia de la excavación, entre otros, refiriéndose al carácter prácticamente desconocido del yacimiento pues, según él, únicamente había sido visitado por Roland de Vaux y Nelson Glueck. Lo cierto, sin embargo, es que Tulul adh-Dhahab había sido objeto de diversas prospecciones más o menos sistemáticas desde finales del siglo XIX y a lo largo de la primera mitad del siglo XX, más allá de las llevadas a cabo por de Vaux y Glueck (véase, por ejemplo, Merri11 1881; Dalman 1928-1942; Noth 1956). Sin embargo, su estudio arqueológico sistemático se inició mucho más tarde, en la década de 1980, gracias a los trabajos de R. L. Gordon (Gordon, Villiers 1983; Gordon 1984) y, sobre todo, a partir de 2005 por parte de un equipo conjunto de las universidades de Dortmund y Basle (Pola et al. 2013).

Consciente de que la empresa planteada en Tulul adh-Dhahab era de mucha mayor envergadura que los trabajos acometidos en Mogaret Dalal, González Echegaray ideó una estrategia para poder llevarla a cabo con éxito. Así, consideraba oportuno que las excavaciones estuviesen dirigidas por el propio Martínez Santa-Olalla, con la ayuda de su tradicional colaborador Bernardo Sáez Martín, y con un equipo integrado por los arqueólogos de la Casa de Santiago, incluyéndose, por supuesto, él mismo. El objetivo que perseguía colocando a Martínez Santa-Olalla al frente del proyecto era doble. Por una parte, González Echegaray esperaba que la inclusión de una figura de cierto prestigio internacional como la de Martínez Santa-Olalla facilitase la labor de convencer a Dajani para la obtención de los permisos necesarios. Por otra, creía que la ascendencia política y académica de Martínez Santa-Olalla, muy superior a la suya, podía ser de utilidad a la hora de obtener recursos económicos procedentes de la Dirección General de Relaciones Culturales del Ministerio de Asuntos Exteriores, imprescindibles para poder llevar a cabo el proyecto: 
El Director de las excavciones [sic] seria Vd., y podria venir tambien Bernardo, y el resto del equipo lo podríamos formar con gente de la Casa de Santiago, que es el nombre de nuestra casa de Jerusalem. Yo he hablado a Dajani de Vd. El ya le conocía sobre todo creo a través de Sevillano, que era el antiguo embajador, hombre muy aficionado a la Arqueología. Creo que todo podría solucionarse bien y lo que necesitamos es trabajar al Ministro de Asuntos Exteriores (Ayuntamiento de Madrid. Museo de San Isidro. JMSO 40/6/24113).

En caso de haber fructificado el proyecto de excavación en Tulul adh-Dhahab, la trayectoria de González Echegaray hubiese adoptado un rumbo muy distinto al seguido hasta entonces. Especializado en el estudio de la prehistoria cantábrica y del Próximo Oriente, las excavaciones de Tulul adh-Dhahab le hubiesen llevado directamente hasta el campo de la Arqueología Bíblica - conviene recordar en este sentido que las recientes excavaciones alemanas en el lugar señalan que el yacimiento carece de fases prehistóricas, con un primer estrato de ocupación datado ca. 1300-970 a.n.e. González Echegaray se mantuvo siempre al margen del trabajo de campo relacionado con la Arqueología Bíblica, una materia de la que únicamente se ocupó a nivel estrictamente bibliográfico y como consecuencia de diversos encargos editoriales recibidos (veáse, por ejemplo, González Echegaray 2010). El ejemplo de Tulul adh-Dhahab demuestra, no obstante, que contemplaba abiertamente la posibilidad de abandonar, aunque fuese temporalmente, la arqueología prehistórica para dedicarse de pleno a la Arqueología Bíblica. El éxito de los trabajos de Kathleen Kenyon en Jericó (Sala 2014), mencionados expresamente en su correspondencia con Martínez Santa-Olalla, así como su deseo de lograr la mayor repercusión mediática posible para su labor en Jordania y el acceso a subvenciones estatales, son los principales elementos que seguramente explican la voluntad de González Echegaray de reorientar su labor investigadora hacia la Arqueología Bíblica.

Sin embargo, el proyecto de excavación en Tulul adh-Dhahab tuvo una vida muy efímera, puesto que en su carta a Martínez Santa-Olalla de 10 de Marzo de 1961, ya no se refería al mismo sino a sus futuras excavaciones en ElKhiam (Ayuntamiento de Madrid. Museo de San Isidro. JMSO 40/05/24061). Tal y como apuntaba en sus memorias, y fruto de sus contactos con Moshé Stekelis, finalmente optó por iniciar el que a la postre fue su principal proyecto arqueológico en el Próximo Oriente (González Echegaray 2015: 181ss.), abandonando de esa forma la posibilidad de llevar adelante las excavaciones en Tulul adh-Dhahab - Penuel, unas excavaciones que, de haberse realizado, hubiesen adelantado en varias décadas el estudio arqueológico del yacimiento.

\section{Consideraciones finales}

Los testimonios expuestos hasta aquí dejan claro que González Echegaray daba un valor muy importante a las excavaciones en Mogaret Dalal, en tanto que momento fundacional de la arqueología española en el Próximo Oriente. En su opinión, aquellos trabajos contribuyeron a poner fin a lo que él definía como una tendencia al aislamiento en la interioridad geográfica ibérica característica de la arqueología española.

Con todo, aquellas palabras de González Echegaray, aunque ciertas, contribuían a obviar un conjunto de experiencias arqueológicas previas, siempre modestas, en el Próximo Oriente. Así, por ejemplo, es bien conocida la labor anticuarista del diplomático Adolfo Rivadeneyra (1841-1882), quien a lo largo de sus viajes por el Próximo Oriente logró reunir una interesante colección de materiales arqueológicos que en 1877 ingresaron en los fondos del Museo Arqueológico Nacional (Escribano 2002 y 2006). De forma similar, también el P. Bonaventura Ubach aprovechó sus periplos por el Próximo Oriente para reunir una colección de objetos relacionados con la Arqueología Bíblica que dieron origen al Museo Bíblico de Montserrat (Uriach y Vivo 2008; Márquez 2015). La lista puede completarse con otras colecciones menores creadas también durante la primera mitad del siglo XX, como las del Museo Bíblico Tarraconense (Muñoz 2011) o el Museo de Tierra Santa de Santiago de Compostela (Gigirey 1995). Menos conocidas son, por otra parte, las excavaciones que Josep Gibert, discípulo de Pere Bosch Gimpera, llevó a cabo en Tell Balata - Siquem (Israel) en 1930-1931, bajo la dirección de Gabriel Welter y en el contexto de un proyecto frustrado que debía concluir con la creación de una Escuela Catalana de Arqueología en Oriente (Vidal 2016). Ciertamente, ninguno 
de aquellos episodios aislados tuvo una verdadera continuidad ni sirvió para iniciar el desarrollo de una tradición de estudios sobre arqueología del Próximo Oriente en España. Pero tampoco las excavaciones de González Echegaray contribuyeron decisivamente a ese propósito. A pesar de contar con el apoyo de la Casa de Santiago, lo cierto es que la labor arqueológica de González Echegaray en Jordania fue en esencia un empeño solitario, sin el respaldo de las instituciones académicas o de investigación del país, más allá de sus contactos con Martínez Santa-Olalla, lo que limitó considerablemente su influencia en el ámbito científico español. De hecho, tal y como apuntaban Joaquín M. Córdoba y Carmen Pérez Díe, el verdadero despegue de la arqueología española en el Próximo Oriente se produjo en la década de 1980, gracias al impulso surgido directamente de las universidades españolas y que se materializó en las excavaciones en Tell Qara Quzaq (Universitat de Barcelona y Universidad de Murcia), Tell Halula (Universitat Autònoma de Barcelona), Yebel al-Mutawwaq (Universidad de Oviedo), y en los trabajos de prospección realizados en la región del Balih
(Universidad Autónoma de Madrid) (Córdoba y Pérez Díe 2006: 22).

Las excavaciones en Mogaret Dalal, por lo tanto, ocupan un lugar importante en la historia de la arqueología española por su carácter pionero, y poseen un enorme valor, por cuanto su realización implicó la superación de importantes dificultades relacionadas con la ausencia de una tradición española en arqueología oriental. No obstante, y por desgracia, las mismas tuvieron un impacto muy limitado, debido tanto a la ausencia de un decidido apoyo institucional como al relativo aislamiento académico de González Echegaray. En este sentido, su alianza con Martínez Santa-Olalla en detrimento de Almagro tampoco contribuyó a superar esa situación, debido a la decreciente influencia política y académica del primero, tras perder la cátedra de Historia Primitiva del Hombre de la Universidad de Madrid (1954) y verse forzado a abandonar la Comisaría General de Excavaciones Arqueológicas (1955). Las excavaciones en Mogaret Dalala no fueron, en definitiva, la llave que permitiese estructurar definitivamente la investigación arqueológica española en el Próximo Oriente.

\section{Bibliografía}

Almagro, A. (2006a): El Baño de Qusayr 'Amra (Jordania). La arqueología española en Oriente. Nacimiento y desarrollo de una ciencia nueva (J. M. Córdoba, M. C. Pérez Díe, eds.). Ministerio de Cultura, Madrid: 35-39.

- (2006b): Investigaciones arqueológicas en la Ciudadela de Amman. La arqueología española en Oriente. Nacimiento y desarrollo de una ciencia nueva (J. M. Córdoba, M. C. Pérez Díe, eds.). Ministerio de Cultura, Madrid: 41-44.

Brown, J. M., Kutler, L. (2005): Nelson Glueck: Biblical archaeologist and president of Hebrew Union College-Jewish Institute of Religion. Hebrew Union College Press, Cincinnati.

Chevalier, N. (2012): Early Excavations (pre- 1914). A Companion to the Archaeology of the Ancient Near East (2 vols.). (D. T. Potts, ed.). Blackwell, Oxford: 48-69.

Córdoba, J. M., Pérez Díe, C. (2006): La aventura arqueológica de España en Oriente. Nacimiento y desarrollo de una ciencia nueva. La arqueología española en Oriente. Nacimiento y desarrollo de una ciencia nueva (J. M. Córdoba, M. C. Pérez Díe, eds.). Ministerio de Cultura, Madrid: 11-24.

Dalman, G. (1928-1942): Arbeit und Sitte in Palästina, I-VII. Bertelsmann, Gütersloh.

Escribano, F. (2002): Adolfo Rivadeneyra. La diplomacia al servicio del redescubrimiento científico y vital de Oriente. Isimu 5: 45-100.

- (2006): Los viajes por Oriente de Adolfo Rivadeneyra. Sociedad Geográfica Española 24: 98-109.

Gigirey, M. E. (1995): El Museo de Tierra Santa. Origen, tipología de sus fondos y su actual instalación en el convento de San Francisco de Santiago de Compostela. Simposium Monjes y monasterios españoles. Univ. Escorial-María Cristina, El Escorial: 319-340.

Glueck, N. (1939): Explorations in Eastern Palestine, III. ASOR, Philadelphia.

González Echegaray, J. (1964-1966): Excavaciones en la terraza de "El Khiam" (Jordania), (2 vols.). CSIC, Madrid.

— (1969-1970): Sondeos y prospecciones en Mogaret Dalal (Jordania). Ampurias 31-32: 233-240.

— (1978a): "La aportación española a la Arqueología Bíblica", Cuadernos Bíblicos 1: 2-13. 
- (1978b): Orígenes del neolítico sirio-palestino. Universidad de Deusto, Bilbao.

- (1988): La labor arqueológica del Instituto Español Bíblico y Arqueológico de Jerusalén (1956-1988). Estudios Bíblicos 46: 231-248.

- (2006): En el remoto mundo de la Prehistoria: El-Dalal y El-Khiam. La arqueología española en Oriente. Nacimiento y desarrollo de una ciencia nueva (J. M. Córdoba, M. C. Pérez Díe, eds.). Ministerio de Cultura, Madrid: 31-34.

- (2010): La Biblia desde la arqueología. Verbo Divino, Estella.

- (2015): Memorias de Jerusalén (1956-1976). La Casa de Santiago en Jerusalén. El Instituto Español Bíblico y Arqueológico en Tierra Santa. (J. M. Sánchez Caro, J. A. Calvo, eds.). Verbo Divino, Estella: 137-244.

González Urquijo, J., Ibáñez, J. J. (2015): Joaquín González Echegaray, el Khiamiense y los orígenes del Neolítico en el Próximo Oriente. Descubriendo el Antiguo Oriente. Pioneros y arqueólogos de Mesopotamia y Egipto a finales del s. XIX y principios del s. XX. (R. Da Riva, J. Vidal, ed.). Bellaterra, Barcelona: 161-179.

Gordon, R. L. (1984): Telul edh Dhahab Survey (Jordan) 1980 and 1982. Mitteilungen der Deutschen Orient-Gesellschaft zu Berlin 116: 131-137.

—, Villiers, L. E. (1983): Telul edh Dhahab and its environs surveys of 1980 and 1982: a preliminary report. Annual of the Department of Antiquities of Jordan 27: 275-289.

Gracia, F. (2009): La arqueología durante el primer franquismo (1939-1956). Bellaterra, Barcelona.

- (2012): Arqueologia i política. La gestió de Martín Almagro Basch al capdavant del Museu Arqueologic Provincial de Barcelona (1939-1962). Universitat de Barcelona, Barcelona.

Hernando, M. (2015): El Instituto Hispano-Árabe de Cultura y la diplomacia cultural hacia el mundo árabe (1954-1974). El Instituto Hispano-Árabe de Cultura: orígenes y evolución de la diplomacia pública española hacia el mundo árabe. M. Hernando, I. González, B. López (eds.). Agencia Española de Cooperación Internacional para el Desarrollo, Madrid: 17-46.

Márquez, I. (2015): La colección mesopotámica del Museo de Montserrat. Museo de Montserrat, Barcelona.

Mederos, A., Escribano, G. (2011): Julio Martínez Santa-Olalla, Luis Diego Cuscoy y la Comisaría Provincial de Excavaciones Arqueológicas de Canarias Occidentales (1939-1955). Museo Arqueológico de Tenerife, Santa Cruz de Tenerife.

Muñoz, A. (coord.) (2011): Musevm Biblicum Tarraconense. Escua, Barcelona.

Merrill, S. (1881): East of the Jordan: a record of travel and observation in the countries of Moab, Gilead, and Bashan. Bentley, London.

Noth, M. (1956): Das Deutsche Evangelische Institut für Altertumswissenschaft des Heiligen Landes. Lehrkursus 1955. Zeitschrift des Deutschen Palästina-Vereins 72: 31-82.

Ortega, A. I., Quero, S. (2002): Julio Martínez Santa-Olalla. Zona arqueológica 1: 195-213.

Palacio-Pérez, E. (2013): Leslie Gordon Freeman (1935-2012) y Joaquín González Echegaray (19302013): una colaboración que cambió la arqueología prehistórica en España. Complutum 24: 211-214.

Pérez, M. (2007): Las relaciones hispano-jordanas en tiempos del régimen franquista: la dimensión cultural y educativa. Revista de Estudios Internacionales Mediterráneos 3: 21-44.

Pola, T. et al. (2013): A preliminary report of the Tulul adh-Dhahab (Wadi az-Zarqa) survey and excavation seasons 2005-2011. Annual of the Department of Antiquities of Jordan 57: 81-96.

Roldán, L., Blánquez, J. (eds.) (2012): Julio Martínez Santa-Olalla y el descubrimiento arqueológico de Carteia (1953-1961). Universidad Autónoma de Madrid, Madrid.

Sala, M. (2014): The Archaeological Expeditions to Tell es-Sultan (1868-2012). Archaeology en the 'Land of Tells and Ruins'. (B. Wagemakers, ed.). Oxbow Books, Oxord-Philadelphia: 117-130.

Sánchez Caro, J. M., Calvo, J. A. (eds.) (2015): La Casa de Santiago en Jerusalén. El Instituto Español Bíblico y Arqueológico en Tierra Santa. Verbo Divino, Estella.

Schlanger, N., Nordbladh, J. (eds.) (2008): Archives, Ancestors, Practices: Archaeology in the Light of its History. Berghahn Books, New York.

Slayton, J. C. (1992): Penuel. The Anchor Bible Dictionary, 5. (D. N. Freedman, ed.). Doubleday, New York: 223.

Straus, L. G. (2013): Joaquín González Echegaray (1930-2013). Journal of Anthropological Research 69: 161-165.

Uriach, J., Vivo, J. (eds.) (2008): La col-lecció egípcia del Museu de Montserrat. Museo de Montserrat y Societat Catalana d'Egiptologia, Barcelona. 
Varela Dafonte, J. A. (1999): A mi manera. Recuerdos de una vida en la Carrera. Trabe, Oviedo.

Vidal, J. (2013): Diccionario biográfico del Orientalismo Antiguo en España. Universidade da Coruña, A Coruña.

- (2014): Julio Martínez Santa-Olalla y la colección de antigüedades mesopotámicas del Seminario de Historia Primitiva del Hombre. Aula Orientalis 32: 151-164.

- (2016): La escuela de arqueología del Mediterráneo Oriental que no pudo ser. Aproximación a la figura de Josep Gibert i Buch. Archivo Español de Arqueología 89: 181-191.

Zurinaga, S. (2009): La campaña de Nubia en la prensa escrita de la época. 1960-1966. 120 años de arqueología española en Egipto. Sociedad estatal de conmemoraciones culturales, Madrid: 46-53. 